\title{
Treating the "Untreatable". Recent advances in chronic thromboembolic pulmonary hypertension
}

\author{
Inbal Shafran ${ }^{1}$ and Irene Lang ${ }^{2}$
}

${ }^{1}$ The Pulmonary institute, Chaim Sheba Medical Center, Tel-Hashomer, Israel and the ${ }^{2}$ Department of Internal Medicine II, Division of Cardiology, Medical University of Vienna, Vienna, Austria

Correspondence: Irene Lang, Medical University of Vienna, Internal Medicine II, Division of Cardiology, Währinger Gürtel 18-20, 1090 Vienna, Austria

E-mail: irene.lang@meduniwien.ac.at

\section{Take-home message:}

Main treatment for CTEPH is Pulmonary Endarterectomy, a complex surgical procedure, that is performed in roughly half of all CTEPH patients. Refinements of Medical Treatments and Balloon Pulmonary Angioplasty have emerged as effective treatment strategies for the remaining patients who had no options in the past.

Chronic thromboembolic pulmonary hypertension (CTEPH) is thought to result from incomplete resolution of pulmonary thromboemboli that undergo organisation into fibrous tissue within pulmonary arterial branches, filling pulmonary arterial lumina with collagenous obstructions. The treatment of choice is pulmonary endarterectomy (PEA) with low post-operative mortality and good long-term survival in expert hands. Patients ineligible for PEA or who have recurrent or persistent pulmonary hypertension after surgery have been previously the "Untreatable". Modern CTEPH management has now a solution for those previous no-option patients: balloon pulmonary angioplasty (BPA), and targeted medical therapies. Riociguat has been approved for inoperable CTEPH, and persistent-recurrent PH after PEA, and SC Treprostinil has been efficacious in a randomized controlled trial of very severe $\mathrm{CTEPH}$. Observational studies report that BPA improves haemodynamic, symptoms and functional capacity in patients with CTEPH, but controlled trials with long-term follow-up are needed. Complications include haemoptysis, wire injury, vessel dissection, vessel rupture, reperfusion pulmonary oedema, pulmonary parenchymal bleeding and haemorrhagic pleural effusions. This review summarises available evidence for PEA, BPA, and medical therapy, patient selection, peri-procedural imaging and technical refinements achieved by CTEPH teams, and discusses future management of CTEPH.

\section{Introduction}

Chronic thromboembolic pulmonary hypertension (CTEPH) is a rare disease of the pulmonary vasculature which is classified as a distinct entity (Group 4) of pulmonary hypertension (PH) (1). CTEPH is believed to develop when a pulmonary embolism does not resolve and transforms into fibrous tissue that occludes major pulmonary arteries. A concomitant small-vessel arte- riopathy plays an important role in the development of persistent $\mathrm{PH}$ after surgical pulmonary endarterectomy (PEA) and survival.

Early diagnosis and treatment by a multidisciplinary team are essential. Screening is based on ventilation/ perfusion lung scanning, and diagnosis is made by imaging typical CTEPH lesions with angiography, best by invasive digital subtraction angiography or direct injection. Computed tomography is emerging to provide 
similar quality images as invasive angiography in the future, including parenchymal lung images as well as images of the heart and the great vessels for differential diagnoses. The CTEPH team should then address the question whether the gold-standard treatment PEA as a potentially curative intervention is feasible with an in-hospital mortality rate $<5 \%$. About $40-50 \%$ of patients with CTEPH is no surgical candidates or cannot undergo surgery at an acceptably low in-hospital mortality rate, and $17-31 \%$ of patients after PEA experience persistent/recurrent PH. Modern CTEPH management has now a solution for those previous no-option patients: balloon pulmonary angioplasty can be performed, and targeted medical therapies can be given.

\section{Pulmonary Endarterectomy - An old technique newly stimulated}

PEA remains the gold standard treatment with the option of potential cure with mortality rates as low as $2 \%$ in specialised centers (Table 1) (1, 2). Elligibility for PEA should be determined by a CTEPH team consisting of surgeons, $\mathrm{PH}$ specialists, radiologists and interventionists. Tradionally, PEA was limited to patients with proximal disease and localisation of most proximal clot has been the main determinant of PEA eligibility $(2,3)$. Experienced centers have advanced their skills to allow surgical treatment for patients with more distal disease (4). Moreover, there is a growing understanding that
PEA may lead to RV afterload reduction even in patients with high PVR and distal disease, in combination with other treatments (2).

Peri-procedural complications include stroke, bleeding, arrhythmia, pericardial and pleural effusions and post-operative reperfusion pulmonary edema (5). Reperfusion edema occurs in $5-20 \%$ of patients, especially in patients with high pre-operative pulmonary pressure $(2,6,7)$. When supportive treatment with mechanical ventilation, diuresis and drugs approved for $\mathrm{PAH}$ are not enough, ECMO may be indicated $(2,8$, 9). ECMO both intra and post-operative has become standard of care in centers performing high-risk PEA $(2,8,9)$.

Pre- and post-operative PVR, pulmonary vasoreactivity, as well as age, comorbidities and functional status are factors assisting in the prediction of post-operative outcomes $(10,11,12)$.

Persistent/recurrent $\mathrm{PH}$ after PEA is a major determinant of poor prognosis and functional capacity for CTEPH patients undergoing PEA $(7,13)$. According to the European registry, $16.7 \%$ of patients are diagnosed with persistent/recurrent PH after PEA (14). The ability to predict which patients are prone to develop such condition is of major practical importance. A concomitant secondary microvasculopathy in addition to major pulmonary artery obstruction has been suggested as one of the mechanisms leading to persistent/recurrent $\mathrm{PH}$ after PEA (2). Recently Gerges et al. have confirmed the role of preoperative pulmonary artery pres-

\begin{tabular}{|c|c|c|c|c|c|c|c|}
\hline Treatment & Source & $\begin{array}{c}\text { Year of } \\
\text { public ation }\end{array}$ & $\begin{array}{c}\text { Number } \\
\text { of } \\
\text { patients }\end{array}$ & $\begin{array}{c}\text { Change } \\
\text { in 6MWD } \\
(*)\end{array}$ & $\begin{array}{c}\text { Change } \\
\text { in PVR } \\
(*)\end{array}$ & $\begin{array}{c}\text { Change } \\
\text { in mPAP } \\
(*)\end{array}$ & $\begin{array}{l}\text { Peripro- } \\
\text { cedural } \\
\text { mortality }\end{array}$ \\
\hline \multirow[t]{6}{*}{ PEA } & Italian registry (39) & 2016 & 554 & $41 \%$ & $-71 \%$ & $-48 \%$ & $8.50 \%$ \\
\hline & French reference center (40) & 2018 & 150 & $29 \%$ & $-60 \%$ & $-41 \%$ & $2.90 \%$ \\
\hline & San Diego Health center (41) & 2012 & 500 & - & $-64 \%$ & $-43 \%$ & $2.20 \%$ \\
\hline & $\begin{array}{l}\text { United Kingdom National Cohort } \\
\text { (42) }\end{array}$ & 2016 & 880 & $36 \%$ & $-62 \%$ & $-43 \%$ & $2.4 \%$ ** \\
\hline & $\begin{array}{l}\text { German registry - } \\
\text { Bad Nauheim (43) }\end{array}$ & 2017 & 236 & - & - & - & $2.50 \%$ \\
\hline & European CTEPH registry (6) & 2011 & 386 & - & $-66 \%$ & - & $4.60 \%$ \\
\hline \multirow[t]{3}{*}{ BPA } & French reference center (29) & 2019 & 184 & $11 \%$ & $-45 \%$ & $-28 \%$ & $2.20 \%$ \\
\hline & Hannover \& Bad Nauheim (44) & 2017 & 56 & $9 \%$ & $-26 \%$ & $-18 \%$ & $1.80 \%$ \\
\hline & Japanese multicenter registry (36) & 2017 & 308 & $35 \%$ & $-66 \%$ & $-48 \%$ & $2.60 \%$ \\
\hline Riociguat & CHEST 1 (19) & 2013 & 261 & $13 \%$ & $-31 \%$ & $-9 \%$ & - \\
\hline Bosentan & BENEFiT (21) & 2008 & 157 & $0 \%$ & $-24 \%$ & $-5 \%$ & - \\
\hline Macitentan & MERIT-1 (23) & 2017 & 80 & $10 \%$ & $-16 \%$ & $-4 \%$ & - \\
\hline Treprostinil SC & CTREPH (25) & 2019 & 105 & $15 \%$ & $-34 \%$ & $-7 \%$ & - \\
\hline $\begin{array}{l}\text { Oral } \\
\text { combinations }^{* * *}\end{array}$ & $(45)$ & 2018 & 117 & $13 \%$ & $-41 \%$ & $-13 \%$ & - \\
\hline
\end{tabular}


sure waveform analysis to predict secondary microvasculopathy and outcomes prior to PEA (15).

\section{Advances in Medical Treatments for CTEPH}

The initial step in the management of CTEPH is appropriate anticoagulation. Current guidelines suggest that effective anticoagulation over at least 3 months should precede a CTEPH diagnosis. 3 months is the minimal guideline-recommended treatment duration for acute pulmonary embolism. Furthermore, guidelines advise to continue lifelong anticoagulation to prevent recurrent thrombosis. While there are no large randomized trials regarding the preferable type of anticoagulation for CTEPH patients, recent registries point to beneficial effects of Vitamin $\mathrm{K}$ antagonists as compared with DOACs (16), despite greater safety of direct oral anticoagulants (DOACs) (17). Post-PEA functional and hemodynamic outcomes appeared unaffected by anticoagulant choice. Bleeding events were similar, but recurrent VTE rates were higher in patients receiving DOACs (16).

Medical treatment for CTEPH patients is required in many patients, particularly in those who are no candidates for PEA because of distal location of vascular disease, or because they carry an unfavorable risk-benefit ratio for major surgery. Furthermore, medical treatments are considered for patients with severe hemodynamic compromise prior to PEA or balloon pulmonary angioplasty (BPA), and after mechanical interventions in those with persistent/recurrent PH (18).

Riociguat was the first drug with clinical effectiveness to be approved for the treatment of inoperable CTEPH, or persistent/recurrent $\mathrm{PH}$ after $\operatorname{PEA}(19,20)$. The drug is a stimulator of soluble guanylate cyclase (sGC) with both a direct effect and an indirect effect by sensitizing GC receptors to endogenous nitric oxide (NO). Improved exercise capacity (EC) and PVR were shown in the CHEST-1 and CHEST-2 trials (19).

The BENEFiT trial, (Bosentan Effects in iNopErable Forms of chronic Thromboembolic pulmonary hypertension), a randomized, placebo-controlled trial with the Endothelin receptor antagonists (ERA) Bosentan did not meet the primary combined endpoint of 6MWD and decrease in PVR (21). Positive results where demonstrated for the use of bosentan as bridging therapy before PEA (22). The MERIT-1 trial, examining the effect of macitentan in inoperable CTEPH showed improved PVR and 6MWD, however no change in WHO-FC (23). Actelion-Janssen has withdrawn their application for approval of macitentan for the treatment of CTEPH.

A significant advancement in medical treatment of CTEPH was made in the CTREPH trial, examining the effect and the safety of subcutaneous (SC) treprostinil for severe CTEPH $(18,24)$. Treprostinil treatment was evaluated for both inoperable CTEPH and persistent/ recurrent $\mathrm{PH}$ after $\mathrm{PEA}$. To ensure blinding of the study a high dose of the drug (uptitrated to $30 \mathrm{ng} / \mathrm{kg} / \mathrm{min}$ ) was compared with a low dose peaking at $5 \mathrm{ng} / \mathrm{kg} / \mathrm{min}$. About $30 \%$ of patients were treated concomitantly with other $\mathrm{PH}$ related oral medications, such as riociguat, ERAs and PDE5 inhibitors. The study demonstrated significant changes in 6MWD, hemodynamics and most significantly, WHO-FC $(18,25)$. SC treprostinil, although not officially approved for the treatment of CTEPH, is used for patients who require medical treatment and can either not tolerate riociguat or are high-risk patients, defined by a low 6MWD and unfavorable hemodynamic criteria such as a PVR $>800$ and dynes.s.cm-5 and $\mathrm{mPAP} \geq 40 \mathrm{mmHg}$ (18).

\section{Balloon pulmonary angioplasty - a new technique changing $\mathrm{CTEPH}$}

BPA treatment, first introduced in 2001 (26), is a percutaneous balloon intervention breaking intraluminal webs and bands without dissecting medial vessel layers. The procedure has been improved and refined over the years with better results and safety profiles, using a sequential approach with $4-7$ sessions $(27,28)$. Mainly developed in Japan, the procedure is now introduced and offered to European centers with favourable results $(2,29,30,31,32)$. Current guidelines recommend BPA for patients with either inoperable disease or those with unfavourable risk-benefit ratio for PEA (1). However, more and more centers are now offering this option to patients with persistent or recurrent $\mathrm{PH}$ after PEA surgery and in specific cases as combined treatments, prior to, during or after $\operatorname{PEA}(33,34)$.

In Japan BPA is preferred over PEA surgery. More and more data are collected regarding safety and effectiveness (30), for example in the Euroeopan BPA Registry (NCT03245268). In a recent Japanese study, BPA alone or in combination with PEA has been shown to improve prognosis when compared to patients treated with PEA alone or medical treatment alone (30). Survival of inoperable patients diagnosed in the BPA era is better than previous (35).

BPA protocols vary from one center to the other, but repeat sessions are required. The main imaging assessment used to assess the patients is pulmonary angiography, however CT scans, with 3D reconstructions and OCTs have provided important anatomic insights $(2,28)$. Routine use of OCT or IVUS during BPA has not been recommended.

According to a recent Japanese registry mPAP is reduced by about $20 \mathrm{mmHg}$ to levels below $25 \mathrm{mmHg}$, with significant reduction in the need for other $\mathrm{PH}$ related medications and supplemental oxygen (36). The French BPA experience has documented improved hemodynamics as well as improved 6MWD and NYHA functional class after $5.2 \pm 2.4$ BPA sessions. mPAP 
has decreased by $26 \%$ and PVR by $43 \%$ when compared to baseline values 29. BPA has also been shown to improve comorbidities such as metabolic function and renal function in parallel to improvement in pulmonary hemodynamics (37).

Complication rates have been drastically reduced in recent years with the use of balloons that have a smaller diameter than the lumen of the target vessel, tapered balloons, soft wires, and a stepwise approach (2). Complications, including bleeding, wire-induced pulmonary artery perforation and reperfusion edema occur in up to $10 \%$ of sessions however 30 -day mortality is as low as $1-2 \%(2,36,28,38,29)$.

\section{Future perspectives for CTEPH management}

Despite all advances, there are still several challenges in CTEPH management that have to be faced. First, diagnosis remains hard and best accomplished if one thinks about CTEPH in the setting of major acute pulmonary embolism. Machine learning algorithms are being developed to identify CTEPH cases as they present under the clinical picture of acute PE in emergency rooms. Once diagnosed, the next step is the CTEPH team decision. Multidisciplinary teams face challenges which are case-loads, logistics, and cost. Patient management is shifting from the simple question of PEA or no PEA to multimodality treatment choices (Figure 1). Patients who were labelled inoperable may be found operable upon a second assessment (5). Patients who are inoperable or have persistent / recurrent $\mathrm{PH}$ post-surgery may benefit from a multitude of inter- ventions including BPA, oral medical treatment in different combinations and SC Treprostinil in severe cases (18). Treatment is increasingly individualised according to anatomical disease location, response to different treatments, personal preferences and treatment availabilities.

Refined BPA is a safe and effective treatment option for patients with distal disease, patients with comorbidities, as well as patients with recurrent/persistent $\mathrm{PH}$ after surgery $(14,33,34)$. Randomized studies will have to compare the role of BPA with PEA in suitable patients.

\section{Conflicts of Interest}

IML has relationships with drug companies including AOPOrphan Pharmaceuticals AG, Actelion-Janssen, $M S D$, Medtronic, and Ferrer. In addition to being investigator in trials involving these companies, relationships include consultancy service, research grants, and membership of scientific advisory boards. Table $1-R e-$ ported effects of PEA, BPA and medical treatments in CTEPH.

\section{References}

1. Galie N, Humbert M, Vachiery JL, et al. 2015 ESC/ERS Guidelines for the diagnosis and treatment of pulmonary hypertension: The Joint Task Force for the Diagnosis and Treatment of Pulmonary Hypertension of the European Society of Cardiology (ESC) and the European Respiratory Society (ERS): Endorsed by: Association for European Paediatric and Congenital Cardiology (AEPC), International Society for Heart and Lung Transplantation (ISHLT). The European respiratory journal 2015; 46(4): 903-75. doi 10.1183/13993003.01032-2015

2. Wilkens H, Konstantinides S, Lang IM, et al. Chronic thromboem-




bolic pulmonary hypertension (CTEPH): Updated Recommendations from the Cologne Consensus Conference 2018. Int J Cardiol 2018; 272S: 69-78. doi: 10.1016/j.ijcard.2018.08.079 [published Online First: 2018/09/10]

3. Siennicka A, Darocha S, Banaszkiewicz M, et al. Treatment of chronic thromboembolic pulmonary hypertension in a multidisciplinary team. Ther Adv Respir Dis 2019; 13: 1753466619891529. doi: 10.1177/1753466619891529 [published Online First: 2019/12/28] 4. D'Armini AM, Morsolini M, Mattiucci G, et al. Pulmonary endarterectomy for distal chronic thromboembolic pulmonary hypertension. The Journal of thoracic and cardiovascular surgery $2014 ; 148(3)$ : 1005-11; 12 e1-2; discussion 11-2. doi: 10.1016/j.jtcvs.2014.06.052 [published Online First: 2014/08/19]

5. Ranka S, Mohananey D, Agarwal N, et al. Chronic Thromboembolic Pulmonary Hypertension-Management Strategies and Outcomes. J Cardiothorac Vasc Anesth 2019 doi: 10.1053/j.jvca.2019.11.019 [published Online First: 2019/12/31]

6. Mayer E, Jenkins D, Lindner J, et al. Surgical management and outcome of patients with chronic thromboembolic pulmonary hypertension: results from an international prospective registry. The Journal of thoracic and cardiovascular surgery 2011; 141(3): 702-10. doi: 10.1016/j.jtcvs.2010.11.024

7. Freed DH, Thomson BM, Berman M, et al. Survival after pulmonary thromboendarterectomy: effect of residual pulmonary hypertension. The Journal of thoracic and cardiovascular surgery 2011; 141(2): 383-7. doi: 10.1016/j.jtcvs.2009.12.056 [published Online First: 2010/05/18]

8. Kelava M, Koprivanac M, Smedira N, et al. Extracorporeal Membrane Oxygenation in Pulmonary Endarterectomy Patients. J Cardiothorac Vasc Anesth 2019; 33(1): 60-69. doi: 10.1053/j. jvca.2018.06.025 [published Online First: 2018/08/27]

9. Martin-Suarez S, Gliozzi G, Fiorentino M, et al. Role and management of extracorporeal life support after surgery of chronic thromboembolic pulmonary hypertension. Ann Cardiothorac Surg 2019; 8(1): 84-92. doi: 10.21037/acs.2019.01.02 [published Online First: 2019/03/12]

10. Bonderman D, Skoro-Sajer N, Jakowitsch J, et al. Predictors of outcome in chronic thromboembolic pulmonary hypertension. Circulation 2007; 115(16): 2153-8. doi: CIRCULATIONAHA.106.661041 [pii] 10.1161/CIRCULATIONAHA.106.661041 [published Online First: 2007/04/11]

11. Dartevelle $P$, Fadel E, Mussot $S$, et al. Chronic thromboembolic pulmonary hypertension. The European respiratory journal 2004; 23(4): 637-48. [published Online First: 2004/04/16]

12. Skoro-Sajer N, Hack N, Sadushi-Kolici R, et al. Pulmonary vascular reactivity and prognosis in patients with chronic thromboembolic pulmonary hypertension: a pilot study. Circulation 2009; 119(2): 298-305. doi: CIRCULATIONAHA 108.794610 [pii]

10.1161/CIRCULATIONAHA.108.794610 [published Online First: 2009/01/02]

13. Sakurai Y, Takami Y, Amano K, et al. Predictors of Outcomes After Surgery for Chronic Thromboembolic Pulmonary Hypertension. Ann Thorac Surg 2019; 108(4): 1154-61. doi: 10.1016/j.athoracsur.2019.03.100 [published Online First: 2019/05/11]

14. Pepke-Zaba J, Delcroix M, Lang I, et al. Chronic thromboembolic pulmonary hypertension (CTEPH): results from an international prospective registry. Circulation 2011; 124(18): 1973-81. doi: CIRCULATIONAHA.110.015008 [pii]

10.1161/CIRCULATIONAHA.110.015008 [published Online First: 2011/10/05]

15. Gerges C, Gerges M, Friewald R, et al. Microvascular Disease in Chronic Thromboembolic Pulmonary Hypertension: Hemodynamic Phenotyping and Histomorphometric Assessment. Circulation 2020 doi: 10.1161/CIRCULATIONAHA.119.041515 [published Online First: 2020/01/04]
16. Bunclark K, Newnham M, Chiu YD, et al. A multicenter study of anticoagulation in operable chronic thromboembolic pulmonary hypertension. J Thromb Haemost 2020; 18(1): 114-22. doi: 10.1111/ jth.14649 [published Online First: 2019/09/27]

17. Gavilanes-Oleas FA, Alves JL, Jr., Fernandes CJC, et al. Use of direct oral anticoagulants for chronic thromboembolic pulmonary hypertension. Clinics (Sao Paulo) 2018; 73: e216. doi: 10.6061/ clinics/2018/e216 [published Online First: 2018/05/24]

18. Sadushi-Kolici R, Lang IM. Treprostinil for the treatment of chronic thromboembolic pulmonary hypertension. Expert Rev Respir Med 2019: 1-7. doi: 10.1080/17476348.2019.1652094 [published Online First: 2019/09/24]

19. Ghofrani HA, D'Armini AM, Grimminger F, et al. Riociguat for the treatment of chronic thromboembolic pulmonary hypertension. The New England journal of medicine 2013; 369(4): 319-29. doi: 10.1056/NEJMoa1209657

20. Pepke-Zaba J, Jansa P, Kim NH, et al. Chronic thromboembolic pulmonary hypertension: role of medical therapy. The European respiratory journal 2013; 41(4): 985-90. doi: 10.1183/09031936.00201612 [published Online First: 2013/02/12]

21. Jais $X$, D'Armini $A M$, Jansa $P$, et al. Bosentan for treatment of inoperable chronic thromboembolic pulmonary hypertension: BENEFiT (Bosentan Effects in iNopErable Forms of chronlc Thromboembolic pulmonary hypertension), a randomized, placebo-controlled trial. Journal of the American College of Cardiology 2008; 52(25): 2127-34. doi: 10.1016/j.jacc.2008.08.059

22. Reesink HJ, Surie S, Kloek JJ, et al. Bosentan as a bridge to pulmonary endarterectomy for chronic thromboembolic pulmonary hypertension. The Journal of thoracic and cardiovascular surgery 2010; 139(1): 85-91. doi: 10.1016/j.jtcvs.2009.03.053 [published Online First: 2009/08/08]

23. Ghofrani HA, Simonneau G, D'Armini AM, et al. Macitentan for the treatment of inoperable chronic thromboembolic pulmonary hypertension (MERIT-1): results from the multicentre, phase 2, randomised, double-blind, placebo-controlled study. Lancet Respir Med 2017; 5(10): 785-94. doi: 10.1016/S2213-2600(17)30305-3 [published Online First: 2017/09/19]

24. Sadushi-Kolici R JP, Kopec G, Torbicki A, Campean IA, Hoeffken G, Skoro-Sajer N, Simkova I, Karlocai K, Steringer-Mascherbauer R, Samarzija M, Salobir B, Klepetko W, Lindner J, Lang IM. Subcutaneous treprostinil for the treatment of non-operable chronic thromboembolic pulmonary hypertension: a randomized, controlled trial (CTREPH). ESC 2017. 2017

25. Sadushi-Kolici R, Jansa P, Kopec G, et al. Subcutaneous treprostinil for the treatment of severe non-operable chronic thromboembolic pulmonary hypertension (CTREPH): a double-blind, phase 3, randomised controlled trial. Lancet Respir Med 2018 doi: 10.1016/ S2213-2600(18)30367-9 [published Online First: 2018/11/28]

26. Feinstein JA, Goldhaber SZ, Lock JE, et al. Balloon pulmonary angioplasty for treatment of chronic thromboembolic pulmonary hypertension. Circulation 2001; 103(1): 10-3. [published Online First: 2001/01/04]

27. Mizoguchi $H$, Ogawa $A$, Munemasa $M$, et al. Refined balloon pulmonary angioplasty for inoperable patients with chronic thromboembolic pulmonary hypertension. Circ Cardiovasc Interv 2012; 5(6): 748-55. doi: 10.1161/CIRCINTERVENTIONS.112.971077 [published Online First: 2012/11/30]

28. Aoki T, Sugimura K, Tatebe S, et al. Comprehensive evaluation of the effectiveness and safety of balloon pulmonary angioplasty for inoperable chronic thrombo-embolic pulmonary hypertension: longterm effects and procedure-related complications. Eur Heart J 2017; 38(42): 3152-59. doi: 10.1093/eurheartj/ehx530 [published Online First: 2017/10/14]

29. Brenot $P$, Jais $X$, Taniguchi $Y$, et al. French experience of balIoon pulmonary angioplasty for chronic thromboembolic pulmonary 
hypertension. The European respiratory journal 2019; 53(5) doi: 10.1183/13993003.02095-2018 [published Online First: 2019/04/27] 30. Kozu K, Sugimura K, Ito M, et al. Current status of long-term prognosis among all subtypes of pulmonary hypertension in Japan. Int J Cardiol 2020; 300: 228-35. doi: 10.1016/j.ijcard.2019.11.139 [published Online First: 2019/12/10]

31. Kramm T, Wilkens $H$, Fuge J, et al. Incidence and characteristics of chronic thromboembolic pulmonary hypertension in Germany. Clin Res Cardiol 2018; 107(7): 548-53. doi: 10.1007/s00392-0181215-5 [published Online First: 2018/02/17]

32. van Thor MCJ, Lely RJ, Braams NJ, et al. Safety and efficacy of balloon pulmonary angioplasty in chronic thromboembolic pulmonary hypertension in the Netherlands. Neth Heart J 2019 doi: 10.1007/s12471-019-01352-6 [published Online First: 2019/11/30]

33. Wiedenroth CB, Liebetrau C, Breithecker A, et al. Combined pulmonary endarterectomy and balloon pulmonary angioplasty in patients with chronic thromboembolic pulmonary hypertension. The Journal of heart and lung transplantation: the official publication of the International Society for Heart Transplantation 2016; 35(5): 591-6. doi: 10.1016/j.healun.2015.10.030 [published Online First: 2015/11/28]

34. Araszkiewicz A, Darocha S, Pietrasik A, et al. Balloon pulmonary angioplasty for the treatment of residual or recurrent pulmonary hypertension after pulmonary endarterectomy. Int J Cardiol 2019; 278: 232-37. doi: 10.1016/j.ijcard.2018.10.066 [published Online First: 2018/11/10]

35. Taniguchi $Y$, Jais $X$, Jevnikar $M$, et al. Predictors of survival in patients with not-operated chronic thromboembolic pulmonary hypertension. The Journal of heart and lung transplantation: the official publication of the International Society for Heart Transplantation 2019; 38(8): 833-42. doi: 10.1016/j.healun.2019.04.006 [published Online First: 2019/05/20]

36. Ogawa A, Satoh T, Fukuda T, et al. Balloon Pulmonary Angioplasty for Chronic Thromboembolic Pulmonary Hypertension: Results of a Multicenter Registry. Circ Cardiovasc Qual Outcomes 2017; 10(11) doi: 10.1161/CIRCOUTCOMES.117.004029 [published Online First: 2017/11/05]

37. Tatebe S, Sugimura K, Aoki T, et al. Multiple Beneficial Effects of Balloon Pulmonary Angioplasty in Patients With Chronic Thromboembolic Pulmonary Hypertension. Circ J 2016; 80(4): 980-8. doi:
10.1253/circj.CJ-15-1212 [published Online First: 2016/02/26]

38. Jin $Q$, Luo Q, Yang T, et al. Improved hemodynamics and cardiopulmonary function in patients with inoperable chronic thromboembolic pulmonary hypertension after balloon pulmonary angioplasty. Respir Res 2019; 20(1): 250. doi: 10.1186/s12931-019-1211-y [published Online First: 2019/11/11]

39. D'Armini AM, Morsolini M, Mattiucci G, et al. Chronic thromboembolic pulmonary hypertension: From transplantation to distal pulmonary endarterectomy. The Journal of heart and lung transplantation: the official publication of the International Society for Heart Transplantation 2016; 35(6): 827-31. doi: 10.1016/j.heaIun.2015.12.029 [published Online First: 2016/02/10]

40. Tromeur C, Jais X, Mercier O, et al. Factors predicting outcome after pulmonary endarterectomy. PLoS One 2018; 13(6): e0198198. doi: 10.1371/journal.pone.0198198 [published Online First: 2018/06/22]

41. Madani MM, Auger WR, Pretorius $V$, et al. Pulmonary endarterectomy: recent changes in a single institution's experience of more than 2,700 patients. Ann Thorac Surg 2012; 94(1): 97-103; discussion 03. doi: 10.1016/j.athoracsur.2012.04.004 [published Online First: 2012/05/26]

42. Cannon JE, Su L, Kiely DG, et al. Dynamic Risk Stratification of Patient Long-Term Outcome After Pulmonary Endarterectomy: Results From the United Kingdom National Cohort. Circulation 2016; 133(18): 1761-71. doi: 10.1161/CIRCULATIONAHA.115.019470 [published Online First: 2016/04/08]

43. Lankeit M, Krieg V, Hobohm L, et al. Pulmonary endarterectomy in chronic thromboembolic pulmonary hypertension. The Journal of heart and lung transplantation: the official publication of the International Society for Heart Transplantation 2017 doi: 10.1016/j.healun.2017.06.011 [published Online First: 2017/07/29]

44. Olsson KM, Wiedenroth CB, Kamp JC, et al. Balloon pulmonary angioplasty for inoperable patients with chronic thromboembolic pulmonary hypertension: the initial German experience. The European respiratory journal 2017; 49(6) doi: 10.1183/13993003.02409-2016 [published Online First: 2017/06/10]

45. Gabrielly M, Bourlier D, Taniguchi Y, et al. Initial dual oral combination therapy in inoperable chronic thromboembolic pulmonary hypertension (CTEPH). European Respiratory Journal 2018; 52(suppl 62): PA3053. doi: 10.1183/13993003.congress-2018. PA3053 \% J 